\title{
NOVEL NANOPARTICULATE SYSTEMS FOR IDIOPATHIC PULMONARY FIBROSIS: A REVIEW
}

KIRAN R DUDHAT*, HARSHA V PATEL

Department of Pharmaceutics, Gujarat Technological University, Chandkheda, Gujarat, India. Email: kichupatel@gmail.com

Received: 14 July 2020, Revised and Accepted: 26 August 2020

\begin{abstract}
Idiopathic pulmonary fibrosis (IPF) is the model of a substantial and heterogeneous gathering of pneumonic issues, mostly constant and dynamic, normally known as interstitial lung disease. In the course of the most recent couple of decades, IPF has been progressively perceived as a noteworthy neglected therapeutic need in respiratory pharmaceutical and has turned into the focal point of exceptional research action. This is because of the ways that IPF frequency is expanding around the world, with rates (and sadly forecast) that are fundamentally the same as those of numerous types of growth. Clinical research on IPF has been gigantically progressing, coming full circle in the current revelation of two sheltered and compelling medications, now at long last made accessible to patients. Ordinary treatment for lung disease is related to the absence of specificity and access to the typical cells bringing about cytotoxicity, lessened cell take-up, tranquilize obstruction, and quick medication freedom from the body. The rise of nanotechnology has reformed the treatment of lung diseases like IPF. The focal point of nanotechnology is to target abnormal alveolar epithelial cells (AECs) with enhanced bioavailability and diminished poisonous quality. Nanoparticulates have the potential for IPF treatment by increasing particular access to the abnormal AECs because of surface modifiability and littler size. This audit article additionally features the attributes, ongoing advances in the planning of NPs, and helpful results.
\end{abstract}

Keywords: Idiopathic pulmonary fibrosis, Nanoparticulate formulations, Nanoparticles route of administration, Aerodynamic properties.

(C) 2020 The Authors. Published by Innovare Academic Sciences Pvt Ltd. This is an open access article under the CC BY license (http://creativecommons. org/licenses/by/4. 0/) DOI: http://dx.doi.org/10.22159/ajpcr.2020.v13i11.39035

\section{IDIOPATHIC PULMONARY FIBROSIS (IPF)}

IPF is a dynamic fibrous affected interstice pulmonary disorder with a middle survival phase from 2 to 3 years of analysis [1]. IPF is the most widely recognized sort of idiopathic interstitial pneumonia. Although the ailment has been viewed as uncommon, it happens with comparable recurrence to that of stomach, mind, and testicular diseases [2,3]. Solid tissue is supplanted by the adjusted extracellular grid and alveolar engineering is obliterated, which prompts diminished lung consistency, upset gas trade, and at last respiratory disappointment and passing [4].

IPF is a dynamic, deadly sickness, which is constrained to the lungs and happens in grown-up patients with a striking increment in predominance in patients more seasoned than 60 years. Rule records distributed in the years 2000 and 2011 have refined the definition and conclusion of IPF, permitting a positive finding of IPF crosswise over various nations and in this manner permitting substantial scale global multicenter treatment trials [5]. A background marked by smoking is related to an expanded hazard for the advancement of IPF. In any case, the diffuse pneumonic aggravation found in cigarette smokers may serve to increase reactions to other ecological specialists and spot cigarette smokers at more serious hazards for IPF.

\section{Etiologic and epidemiologic parts of IPF}

The etiology of IPF is by definition obscure. In any case, late advances in hereditary qualities and lessons from familial interstitial pneumonia have uncovered various inclining hereditary polymorphisms and changes, including surfactant protein $\mathrm{An}$ and $\mathrm{C}$, telomerase complex, mucin 5B, tollip, and others [1,6] In addition, chance variables are tobacco smoke, reflux and microaspiration, and possibly herpes infections [7] "IPF" might be a misnomer and different ecological operators might cause pneumonic fibrosis in defenseless people [8]. In a huge scale, epidemiological investigations frequency of IPF went from 4.6 to 16.3/100.000/year and predominance from 14.0 to $42.7 / 100.000$. The intrapulmonary statement of perilous tidies, particularly metallic tidies, shows up to play no less than a half part in starting IPF [9].

\section{Diagnosis of IPF}

The analysis of aspiratory hypertension in the setting of IPF can be troublesome. In any case, there is a developing enthusiasm for the assessment for PH in IPF patients, given the critical prognostic data granted and the chance to discount other contributory and modifiable elements, for example, diastolic brokenness [10].

\section{History and physical examination}

IPF for the most part introduces guilefully, with the progressive beginning of a useless hack and dyspnea. Dyspnea is normally the most debilitating indication. Patients may in like manner cry of paroxysmal dry hack which is adamant to antitussive specialists [11]. By physical study, rales were distinguished on chest auscultation in over $80 \%$ of patients. These are ordinarily "dry," end-inspiratory, and "Velcro" in quality and are most predominant in the lung bases. With the movement of the ailment, rales reach out to the upper lung zones. Fringe edema might be seen in the late periods of the illness [12].

\section{Research facility and serological tests}

Positive flowing against atomic antibodies or rheumatoid factor happens in $10-20 \%$ of patients having IPF, however infrequently are concentrate high [13].

\section{Chest radiograph}

On chest radiography, fibrosing alveolitis is portrayed by unpredictable nodular or reticulonodular shadows, which are typically most broad in the lower zones (a key analytic component). Although the chest radiograph is regularly typical in patients with rheumatologic scatters and restricted lung ailment, reciprocal irregularities that might be awry are generally apparent in cryptogenic fibrosing alveolitis [14].

\section{High-resolution computed tomography (HRCT)}

The 2011 IPF rules give refreshed and streamlined IPF indicative criteria that may encourage making a more certain finding. The key investigational device is high-determination figured tomography as an HRCT [15]. High-determination computed tomography of the chest has 
a focal part in the underlying assessment of patients with the suspected IPF and the outcomes enormously impact resulting administration choices [16].

\section{Other investigations}

Other examinations such as bronchoalveolar lavage, transbronchial lung biopsy, serology, and biomarkers investigation ought not to be carried out in symptomatic assessment for IPF toward greater part in people yet might have been suitable to a minority. Versatile access is to enhance the symptomatic product of IPF previously and precisely [17]. Regardless of familiarity with worldwide IPF rules, the process of versatile talk and early diagnosis and administration should be enhanced through the system of master focuses [18].

\section{Comprehend remedial methodologies in IPF}

The indicative criteria (1) prohibition of known reasons for interstitial lung malady (counting connective tissue ailment); (2) normal interstitial pneumonia design to HRCT for patients did not inflict to careful pulmonary biopsy; and (3) particular blends of HRCT with neurotic examples if there should be an occurrence of careful lung biopsy [19].

\section{Treatment}

\section{Pharmacological treatment}

(1) Nintedanib is a triple tyrosine kinase inhibitor at present in clinical advancement, as a potential treatment of IPF [20]. Due to the assumed pathogenesis of IPF and association of vascular and platelet inferred development factor cell-flagging pathways, nintedanib was tried for adequacy against IPF to improve pulmonary fibrosis [21].

(2) Be that as it may, in 2011, pirfenidone was the main medication affirmed to IPF treatment in Europe [22]. Pirfenidone is an immunosuppressant treatment particularly intended to use for IPF [23]. Four key clinical trials upheld the adequacy and bearableness of pirfenidone. The adequacy information, combined with long haul wellbeing information, gives additional confirmation of a clinicallysignificant treatment impact with pirfenidone in IPF patients $[24,25]$. We ponder whether the creators can give information on the capacity of pirfenidone to avoid intensifications of idiopathic pneumonic fibrosis characterized by the accompanying criteria: Inside 30 days compounding of dyspnea, discoveries on high-determination registered tomography, and the nonattendance of an option identifiable reason, for example, disease [26].

(3) This was a twofold visually impaired randomized preliminary where IPF patients got joined azathioprine, prednisolone, and $\mathrm{N}$-acetylcysteine treatment (triple treatment). Along with they were contrasted with fake treatment gathering. This triple treatment, once utilized as often as possible, is along these lines never again suggested for patients with unmistakable IPF [27]. There are, be that as it may, different types of other fibrotic pulmonary maladies, other than IPF, in which provocative illness instruments assume an unmistakable part; for these, calming and immunosuppressant drugs, incorporating triple treatment (azathioprine, prednisolone, and $\mathrm{N}$-acetylcysteine), are powerful medicines [28]

\section{Non-pharmacological treatment}

Oxygen therapy

No information specifically illuminates the utilization of whole haul oxygen treatment in IPF patients. The investigation has reflectively thought about survival in a partner of IPF patients, huge numbers of whom (27\%) got oxygen therapy [29]. There is restricted confirmation exhibiting a change in practice limit in patients with resting hypoxemia utilizing oxygen [30]. Backhanded proof from two extensive randomized preliminaries in obstructive lung infection has shown sensible survival advantage with whole haul oxygen treatment. The suggestion for long haul oxygen treatment of IPF patients and strong clinically huge resting hypoxemia is observed. Restricted information proposes that IPF and emphysema patients are probably going to require whole haul oxygen treatment and that they have huge pneumonic hypertension [31].

Lung transplantation

Now a day, lung transplantation is principally known treatment for IPF that gives the possibility to whole haul survival. However, this must be advised to a little extent of patients because of age conveyance as a viewpoint and continuous co-morbidities as another $[1,16]$.

The suggestion of lung transplantation is suitable for patients with highrisk IPF. The advisory group perceives the significance of recognizing patients with expanded hazard for mortality inside 2 years to incite thought for lung transplantation [16,32]. Study on survival rates for 5 -years after, $50-56 \%$ of patients having IPF were evaluated with lung transplantation [33]. Extra confirmation recommends that patients with aspiratory fibrosis experiencing lung transplantation have good whole haul survival contrasted and other malady signs [33,34].

\section{NANOPARTICULATE SYSTEM}

Nanoscience has been built up as another interdisciplinary science [35]. The presentation of nanotechnology in the course of the most recent two decades has opened the possibility for the research study area of nanomedicine [36]. In the present issue, a late forward movement for nanoparticulate frameworks, along with strong nanoparticles (NPs), polymeric NPs, as well as polymeric self-congregations, is featured as potential perfect medication conveyance frameworks for inadequately dissolvable, ineffectively retained, and labile substances [37]. New capacities emerging from nanosizing, for example, enhanced solvency, targetability, and bond to tissues, are depicted. And also, the utilization of such capacities is in building up another medication conveyance framework [37]. Another trademark capacity of nanoparticulate, the capacity to convey the medication over various natural obstructions to the objective site is of awesome significance and challenges related to NPs formulations are noted, respectively, in Figs. 1 and 2.

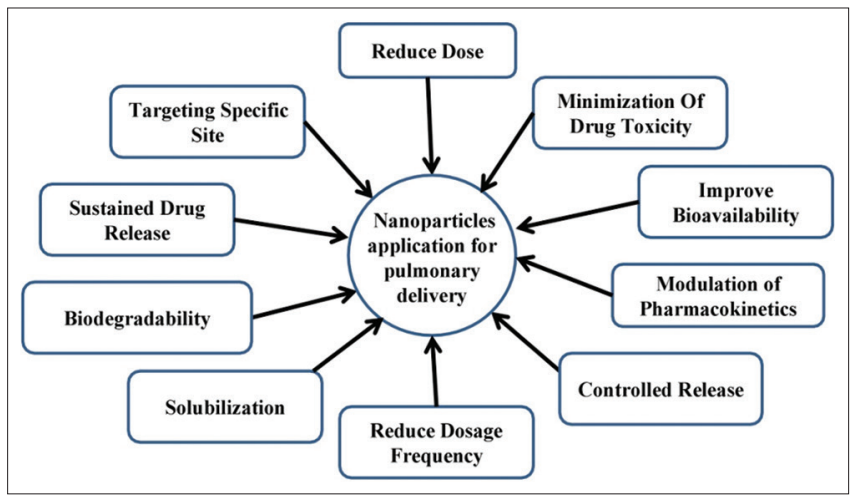

Fig. 1: Significance of nanoparticles for pulmonary applicability

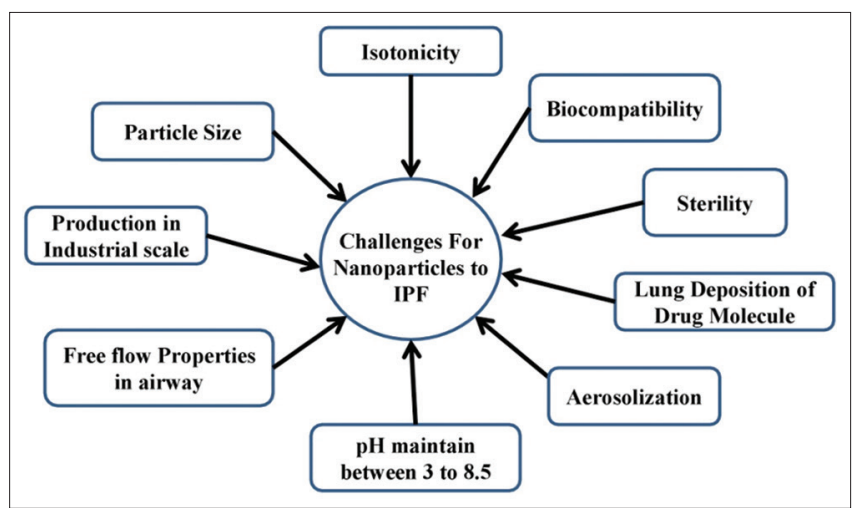

Fig. 2: Challenges for nanoparticles applicable to idiopathic pulmonary fibrosis 


\section{NP formulations}

Nanotechnology takes a shot at issue at measurements in the nanometer scale length (1-100 nm), and along these lines can be utilized for an expansive scope of uses and the making of different sorts of nanomaterials and nano gadgets [38]. In clinical practice, nanotherapeutics has been displayed in the treatment of lung illness with a point of enhancing restorative result, overpowering the multi-medicate opposition, and to lessen the general danger [39]. The nanoscale conveyance frameworks likewise offer the upsides of security from tranquilizing debasement and upgraded focusing on and accessibility at the lung tissue, accordingly restricting access to sound cells, which at last prompt the decreased side effects [40,41]. NPs exhibit some well-defined and delicate characteristics, which have created an attractive and efficient approach for pulmonary delivery of drugs, especially with higher bioavailability, controlled release properties, and enzymatic tolerance. Different novel nanoparticulate systems utilized as a part of the treatment of lung illness have been talked about with a brief basic portrayal delineated in Fig. 3 and Table 1.

\section{Liposomes}

Liposomes are nanosize round vesicles that offer flexible applications because of the concentric nature and capacity to consolidate hydrophilic and hydrophobic medications in a watery center and hydrophobic carbon chains of phospholipids, separately. This outward appearance of liposomes looks somewhat like organic layers [42-44].

Liposomal arrangements have kind attributes, including,

Nontoxic lipids are utilized as a part of liposomal arrangements, and these lipids are financially accessible and effortlessly processed in the body $[45,46]$.

- $\quad$ Easily fabricated in a variety of shapes and types [47]

- A variety of lipid combinations for the preparation of liposomes are available, which provide improved physical stability, dispersion, and destruction in the body [46].

- The liposomes also improve the response of antifibrotic drugs by enhancing permeability, decreased side effects, high-vascular density, and retention time at infected sites $[39,48]$.

Varieties of therapeutic and diagnostic agents are encapsulated in liposomes for targeting the lung disease $[39,48]$.

- Easy modification of surface using biocompatible and inert polymers, which protect the drug from the external environment, reduced opsonization and enhanced circulation time [49,50].

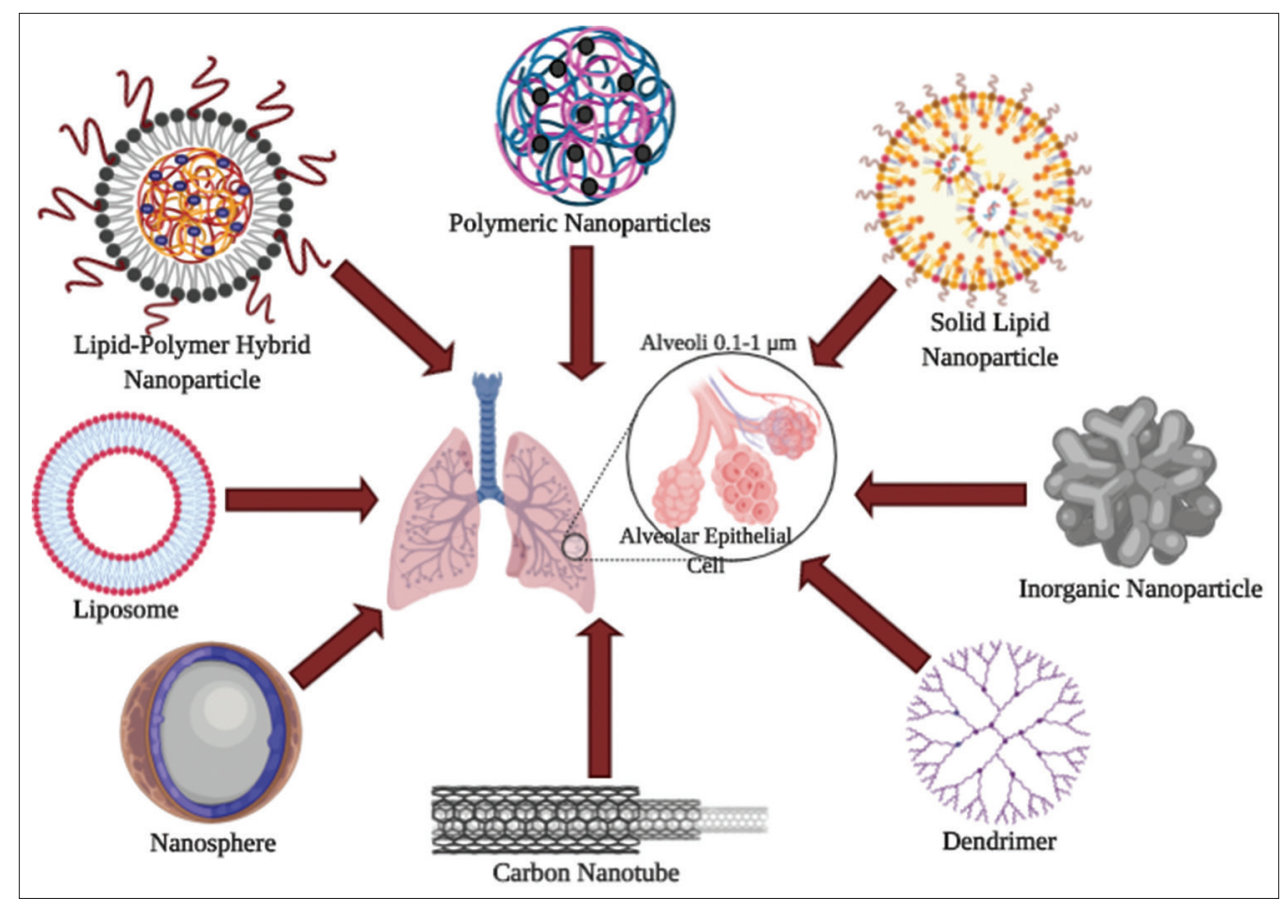

Fig. 3: Different novel nanoparticulate formulations for idiopathic pulmonary fibrosis

Table 1: Different novel nanoparticulate systems for pulmonary applicability

\begin{tabular}{|c|c|c|c|}
\hline Nanoparticulate system & Drug & Significance & Reference \\
\hline Liposome & $\begin{array}{l}\text { Anticancer, } \\
\text { Antibiotic, } \\
\text { Antifibrotic }\end{array}$ & $\begin{array}{l}\text { Improved physical stability, dispersion and destruction in } \\
\text { the body }\end{array}$ & {$[46,47,49-52,88,89]$} \\
\hline $\begin{array}{l}\text { Polymer-based } \\
\text { nanoparticles }\end{array}$ & Antibiotics, Gene delivery & $\begin{array}{l}\text { Targeted and sustained drug delivery, mucoadhesion, lung } \\
\text { deposition, }\end{array}$ & {$[54,55,90]$} \\
\hline Dendrimers & $\begin{array}{l}\text { Gene therapy, anticancer, } \\
\text { antibiotic, } \\
\text { anti-tuberculosis }\end{array}$ & $\begin{array}{l}\text { Self-assembling, polyvalence, electrostatic interactions, low } \\
\text { cytotoxicity, chemical stability, and solubility }\end{array}$ & {$[56-60,91,92]$} \\
\hline Inorganic nanoparticles & Titanium dioxide & Photocatalyst in air and water cleaning & {$[69,70]$} \\
\hline Nanospheres & Anticancer, gene therapy & Physical protection of the drug & {$[73,75,76,93]$} \\
\hline Magnetic nanoparticles & Iron oxide & Biocompatibility and magnetic properties & [79] \\
\hline Solid lipid nanoparticles & vitamin $\mathrm{A}$ & $\begin{array}{l}\text { Physical stability, protection of the drug from degradation, } \\
\text { controlled release and low cytotoxicity }\end{array}$ & {$[80,82]$} \\
\hline $\begin{array}{l}\text { Lipid-polymer hybrid } \\
\text { nanoparticles }\end{array}$ & $\begin{array}{l}\text { Genetic materials, vaccines, } \\
\text { diagnostic imaging agents }\end{array}$ & $\begin{array}{l}\text { physical stability, active targeted drug deliveries, } \\
\text { biocompatibility }\end{array}$ & {$[85-87,94,95]$} \\
\hline
\end{tabular}




\section{Polymer-based NPS}

Polymers are macromolecules comprising of rehashing units of monomers, and adaptable synthetic gatherings of polymers have been used to medicate conjugation and functionalize of polymer-based NPs. Polymer-based NP is an aggregate term which is given to any sort of polymer NP, yet explicitly is connected for nanospheres and nano-capsules. Characteristic and manufactured polymers are both pervasive materials for gathering NPs. Normal polymers including polysaccharides and proteins are profoundly biocompatible and biodegradable. Engineered polymers offer various advantages for various angles. For instance, polyethylene glycol (PEG) polymers have an extraordinary bio-inert, and it is in this way generally utilized for the surface change of NPs [51]. The utilization of polymeric NP for medication conveyance is a procedure that means to advance restorative impacts while limiting unfavorable impacts. PEGylation to be sure lessened to increase the susceptibility of NPs for the resistant cells [51,52]. PEGcovered NPs are additionally ready to infiltrate the respiratory bodily fluid because of their muco-dormant nature. 100 and $200 \mathrm{~nm}$ distance across PEG-covered particles quickly penetrated respiratory bodily fluid [53]. In the interim, cationic polymer, polyethylenimine was used as an effective tie to nucleotides because of their electrostatic proclivity. In light of this property, PEI-based NPs had appeared for compelling to quality conveyance for perpetual respiratory illnesses $[52,53]$.

\section{Dendrimers}

Dendrimers are tediously fanned particles; they show enhanced physicochemical properties contrasted average macromolecules. At the point when all is done, they are very monodispersed NPs, and its size and surface usefulness of the last plan is accurately controllable $[54,55]$. Dendrimers are fit for conveying a lot of medications, and the PEGadjusted dendrimer demonstrates ideal aspiratory ingestion after inward breath [56]. In this manner, they have been broadly utilized for the conveyance of therapeutic effect for incessant lung maladies and anticancer specialists, anti-infection agents, and steroids have been accounted to be conveyed by dendrimers to the lungs $[57,58]$. The extent of most dendrimers utilized as medication bearers differs from 4 to $20 \mathrm{~nm}$. While this size accommodates a proficient disguise by various focused on cells, dendrimers, for the most part, quickly enter into the flow, limiting their maintenance in the lungs $[57,59]$. The conjugation of hydrophobic medication in contact with the surface of PEGylated dendrimer is probably attended quicken pulmonary leeway when contrasted with completely PEGylated dendrimer [60].

\section{Inorganic NPs}

Inorganic NPs incorporate a class of nanocarriers got from metals such as gold and silver, silica, iron oxide, and alumina which hold critical warm, electrical, and attractive attributes [61]. Due to the one of a kind plasmatic and attractive natures, inorganic materials (e.g., iron oxide and gold) create imaging contrast by registered tomography, attractive reverberation, or positron discharge tomography. Thusly, inorganic NPs stages have likewise utilized to demonstrative imaging of illnesses $[62,63]$. Metallic NPs, especially gold NPs, have been broadly examined to quality conveyance because of the way that cationic metal particles effortlessly tie to anionic DNA and RNA atoms $[64,65]$. Disregarding such points of interest, inorganic NPs have indicated just restricted accomplishment in treating endless lung ailments. Albeit mouse having chronic obstructive pulmonary disease (COPD) shows the conveyed effect of gold NPs to alveolar epithelial cells, a high level of lethality to the NPs as noteworthy interest [66]. Be that as it may, low discharge of gold NPs still ruins their clinical applications and long haul ponders. Furthermore, inorganic NPs are not ready to convey a lot of a compound medication. Hence, these confinements ought to be completely tended to precede the clinical preliminaries of inorganic NPs $[67,68]$. Numerous inorganic nanocarriers have a permeable inside structure that works as a medication stockpiling compartment [69].

\section{Nanospheres}

Nanospheres' plans have been considered as a proficient adjuvant in the ongoing years $[70,71]$. The nanospheres are more powerful to induce mucosal safe reactions. These capacities belonging to NPs may be ascribed toward their deep resident period to the nasal hole $[72,73]$. A novel class of engineered bearers composed essentially for quality conveyance was suggested [74]. Nanospheres were orchestrated utilizing quarter poly ethyleneoxide/polypropylenoxide pieces fixated on to the ethylenediamine element. The NPs possess an affirmative charge and effortlessly framed buildings had nucleic acids or plasmids. Afterward, these nanospheres were effectively utilized for inward breath conveyance as a malignancy chemotherapeutic specialist [75]. Testing of in vivo utilizes test using a model such as a lung+ metastasis of mouse colon carcinoma and osteosarcoma bolstered the utilization as favorable immunotherapeutic approach of these nanospheres [76].

\section{Magnetic NPS}

Magnetic NPs could be utilized as imaging and medication conveyance. At the point when such particles collect in the focused in the vicinity, they can be utilized as different operators for attractive reverberation and other complexity imaging. These magnetic NPs may be focused on on-site activity through an outside attractive area. Likewise, the utilization of high force outer attractive area raises the temperature of specific NPs involved basically of metals. Increased temperature can be utilized as executing focused on cells. The magnetic NPs were used as inward breath nearby lung conveyance has additionally been proposed and assessed [77-79].

\section{Solid lipid NPS (SLN)}

This is a steady colloidal bearer's form of lipids strongly stable at room and body temperatures [80]. SLN have broadly been considered for quite a while for potential pneumonic medication conveyance. SLN are nano-scale fluid suspensions arranged from physiological lipids, essentially triglycerides and phospholipids. As the plans depend on utilizing physiological parts, they act less harmful along with greater satisfaction as a pneumonic medication conveyance. Phospholipids are available pervasively to the profound territories from lung and are basic as working by breathing component. Phospholipids-based surfactant proteins introduce on the alveolar surface are basic to keeping up ideal surface pressure along with diminishing erosion in the lung tissue [59].

\section{Lipid-polymer hybrid NPS}

The hybrid NPs introduce properties of the individual segments as well as show synergistic impacts for specific applications. Consequently, the improvement of cutting edge mixture NPs as focused along with request diagnostics and therapeutics sicknesses has quickly turned into a frequent research theme in nanomedicine. The examination center act in the direction of novel classes of programmable cross breed NPs that are decisively designed through amplifies sedate focuses into unhealthy cells, prompting upgraded adequacy and diminished reactions of chemotherapy for the ailment treatment. Specifically, the crossbreed NPs stages can at the same time target unhealthy cells, empower the area imaged by optical strategies, also discharge remedial medications toward sick cells through summon [81]. The hybrid NPs are the multipurpose nano-scaled $(<1000 \mathrm{~nm})$ vehicles created by a self-get together. Half breed NPs are broadly utilized as a part of the treatment of lung malady because of enhanced qualities of managed discharge, directed conveyance, biocompatibility, and delayed dissemination time and productive surface adjustments with ligands [82-84]. Hybrid NPs are made out of three utilitarian parts: (i) A hydrophobic polymeric center in which lipophilic medications are consolidated; (ii) a lipid layer around the center that goes about as a biocompatible shell and as a hindrance to building tranquilize maintenance within the polymeric center; and (iii) a hydrophilic PEG stealth coat around lipid shell. Lipid-PEG shell of mixture NPs assumes a vital part to improve the solidness. The PEG gives useful gatherings to advance change by focusing on ligands $[85,86]$. Another examination uncovered that siRNA stacked PEG joined polyethylene imines NPs focused on integrand receptors of tumor to treat lung sickness. Fuse of medications with the nanocarriers will at last enhance the bioavailability of the medication and will decrease the symptoms identified with bigger measurements of medication [87]. 
Route of nanoparticulate delivery for IPF

Routes of administration significantly influence bioavailability by changing the number of biologic hindrances a medication must cross or by changing the presentation of medication to pumping and metabolic instruments. The general route of administration of NPs is shown in Fig. 4 for IPF infected lung.

\section{Nanoparticulate drug delivery system for oral delivery}

The oral course of an organization is desirable over intravenous or subcutaneous infusion due to the simplicity of organization and patient consistency; however, this course is exceptionally troublesome because the critical intestinal condition can obliterate macromolecules and constrain the retention by way of the gastrointestinal tract. This is conceivable get ready to covered NPs, which can secure delicate medications through the stomach; however, effective move over intestinal layers into the blood supply has gone on the troublesome issue [94]. The patent available as micro and additionally nanospheres arrangement, utilizing a mix of poly-D, L-lactide-co-glycolide to poly-D, L-lactide (80:20) in which half $\mathrm{w} / \mathrm{w}$ of cyclosporin was stacked. This plan indicated moderate arrival of cyclosporin inside $8 \mathrm{~h}$ and was valuable for focusing on cyclosporin to the small digestive tract when managed orally [76].

\section{Nanoparticulate drug delivery system for pulmonary administration}

Real favorable circumstances of inward breath course of medication conveyance locally to the lungs with a specific end goal to treat lung illnesses incorporate direct conveyance of dynamic segments directed toward sick organs and cells, aversion about conceivably dangerous treatment for enters into the circulatory system, along these lines constraining conceivable unfriendly impacts upon other solid organs $[95,96]$. Aspiratory inward breath has been considered as an imperative course of conveyance for NPs $[59,97]$. Pneumonic inward breath empowers higher lung conveyance ( $>3$ times higher) of NPs, when contrasted with a foundational infusion or oral organization [98]. For inward breath, NPs ought to be pensile in a vaporous medium. Fluid suspension and dry powder of NPs are pertinent, and particular gadgets for aerosolization and inward breath are normally enforced. Examples of such medications incorporate corticosteroids, beta-agonists, and anticholinergics [95,99].

\section{Aerodynamic properties}

NPs may be added as a suspension or may be moved for inhalation into dried powders. In both situations, it is important that the aerosols produced out of the suspension or the dry powder formulation display good aerodynamic properties in the required airway regions for adequate deposition. This will play a significant role in chronic pulmonary disease management, as all of the current inhalation formulations must be used at least twice a day due to the comparatively short length of the medication in the lung [100,101]. A particle's geometric diameter alone is not enough to explain its aerodynamic behavior. For example, a tiny particle with a high density will travel with the same velocity as a big, low-density particle. Hence, the aerodynamic diameter was adopted, an arbitrary quantity that sacrifices a particle's physical width, mass, and form. It is defined as the diameter of a spherical particle with a density of one point, having the same settling velocity in the still air as the object [102]. The optimal aerodynamic scale is connected to the target deposition site and therefore differs according to the therapeutic method. The inhalation devices are appropriate for the applications of NPs. Three forms of inhalation devices are commonly available: Nebulizers, dry powder inhalers (DPI), and metered dosage inhalers [80,103].

\section{Nanoparticulate drug delivery system for topical administration}

Colloidal medication conveyance framework is a quickly creating region that had contributed essentially to advance in the region of controlled and focused on tranquilizes conveyance. Colloidal transporters are used one methodology as regulated conveyance about medications to the dermal route [104]. While a vehicle as regulated arrival to dynamic elements along with focusing toward skin layers, nanodisperse frameworks, for example, nanoemulsion, liposome, and lipid NPs are increasing increasingly significant. SLN are studied to real examination found in novel colloidal medication bearers as a topical use [105]. There is limited proof that NPs about a size surpassing $100 \mathrm{~nm}$ cross to skin obstruction inside the dermal compartment. The NPs entrance size is smaller than $100 \mathrm{~nm}$ needed as an assist examination. Lipid NPs or a nanoemulsion are inquired about the treatment of androgenic alopecia, seborrhea, and skin inflammation [106]. Besides, dermal take-up of NPs will be a request of extent lower than take-up through the inward breath or oral courses [107].

\section{Nanoparticulate drug delivery system for parenteral administration}

The parenteral organization to organically dynamic components in the improvement of a regulated conveyance gadget is a noteworthy test inside the region such as necessary to intravenous use, along with lengthy flowing half-life. Organically dynamic components directed in a regulated manner into the blood or tissue are relied upon to display diminished dangerous/reactions contrasted with when the materials are infused as an answer and may decrease the debasement of touchy mixes in the plasma [94]. The intersection of the endothelium will permit foundational treatment by nano-delivery systems (NDS) and besides intravenous organization of aspiratory drugs. The intersection

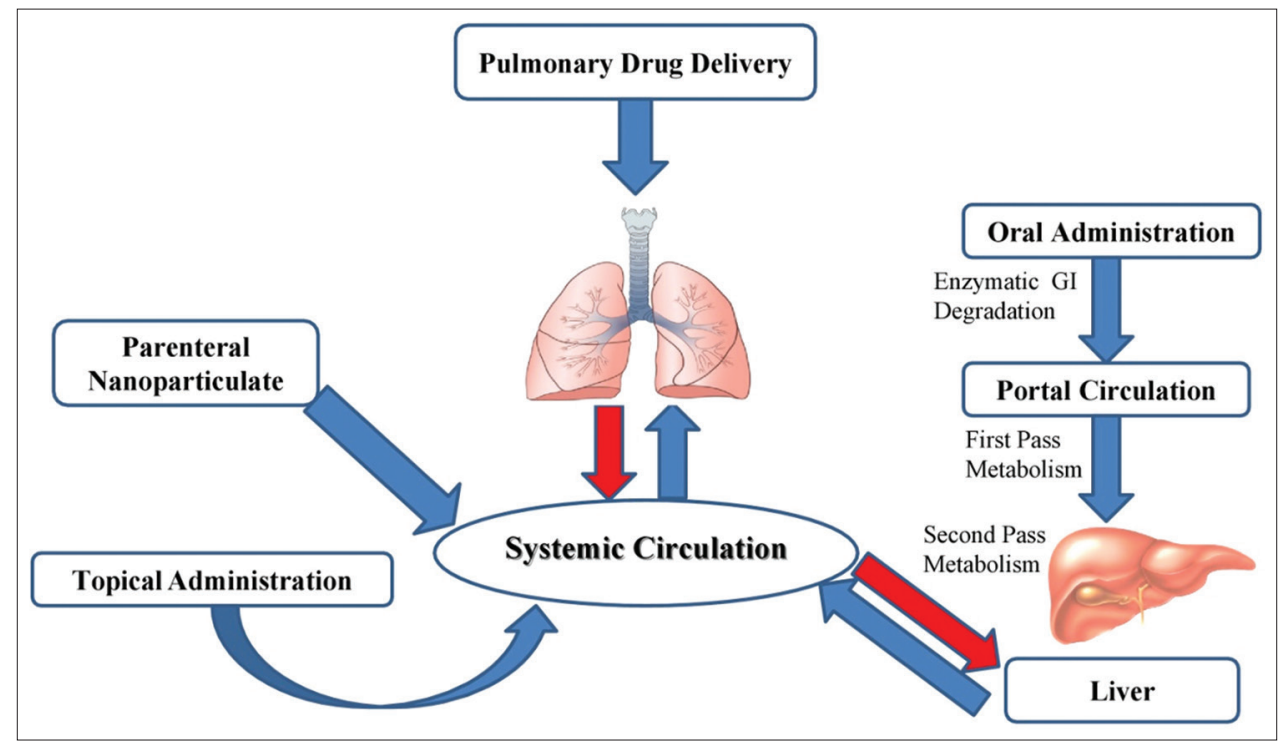

Fig. 4: General route of administration of nanoparticles for idiopathic pulmonary fibrosis 
from air/blood boundary is anyway considerably other noticeable to the alveolar epithelium [108].

\section{RATIONAL FOR DEVELOPMENT OF NP DOSAGE FOR IPF}

\section{Targeting IPF}

Local delivery of the nanostructured lipid carriers formed drug targeted to the lungs could improve its restorative productivity and possibly forestall genuine foundational adverse "off-target effects" [109]. A few investigations contrasting oral with inhalational sedate conveyance utilizing aerosolized polylactide-co-glycolide and alginate NPs stacked with hostile to tubercular medications have shown higher bioavailability of pneumonic medication conveyance over oral and intravenous conveyance [110,111]. Encouraged intersection of the coating liquids and endocytosis of NDS will enhance transfection efficiencies. Especially essential target cells are epithelial cells, neutrophils (e.g., in COPD), and eosinophils (e.g., in asthma) [108]. By targeting NPs other than the oral route, the rate of excretion will be decreased through bypass first metabolism.

\section{Size and surface of NPs}

Nanocarrier systems offer wide potential outcomes regarding structure and size. Be that as it may, the expanded surface territory per unit volume of nanocarriers may build the burst arrival of medication along with propensity toward total reduces the simplicity of their organization to lungs [112]. The particular scope of nano-sized particles is pivotal to decide the adequacy of the treatment for a lung ailment, a few of them may wipe out through organ or overwhelmed through alveolar macrophage. Alveolar macrophages clear the NPs in the scope of over $100 \mathrm{~nm}$ in the lung [59].

\section{Sustain or controlled release drug delivery}

Many of nanoparticulate systems are suggested to get sustains the delivery of drugs. Data available that generally longer time taken for PFD to achieve an insignificant plasma focus recommends a sustainedrelease profile as a liposome in vivo. Histopathology comes about demonstrated that liposomal PFD could lighten obsessive damage in the lung [39].

\section{Enhanced permeability and retention}

Nanoparticulate system improves the response of antifibrotic drugs by enhancing permeability, decreased side effects, high-vascular density, and retention time at infected sites. Liposomal DPI detailing including budesonide and colchicine was figured to accomplish site explicit focused on a conveyance with delayed living arrangement time in the lungs and to accomplish most extreme respirable division with enhanced dispersibility which may assume a promising job in viable administration of idiopathic pneumonic fibrosis $[39,48]$.

\section{Improved drug solubility and stability}

NPs can build sedate solubility and stability and also giving great medication stacking for both hydrophilic and lipophilic medications. On the other hand, the expansive group of non-reversible NPs contains atoms with solid sub-atomic cooperation, for example, covalent or metallic bonds, which give a high level of stability, subsequently encouraging their assembling for business purposes, yet are increasingly inflexible in their blend along with handling [113]. NK911 is doxorubicin (DOX)-exemplified micelles from a copolymer of PEG-DOX-conjugated poly (aspartic corrosive), and Genexol-PM is paclitaxel encapsulated PEG-PLA micelle definition. Polymer micelles have a few favorable circumstances over other medication conveyance frameworks, including expanded medication solvency, delayed course half-life, particular amassing at tumor locales, and lower lethality [114].

\section{Surface properties (bioavailability and penetration)}

Nanoparticulate drug delivery reduces the amount of drug which may penetrate healthy tissues along with reduces systemic toxicity. Various investigations have demonstrated that the nanotransporter can enhance oral bioavailability of inadequately bioavailable medications as well as change the in vivo dissemination by ensnared drugs. Oral deliverability of poor bioavailable drug DOX was improved by polyelectrolyte-coated liposomes $[115,116]$.

\section{Minimize toxicity risks}

The production of NPs with ideal freedom attributes will limit toxicity chances by decreasing the length of the presentation. Making particles with ideal leeway qualities will limit toxicity risk and lessening worries of NPs and nano-sized atoms impedance by diminishing the span of introduction [117]. Camptothecin (CPT) has clinical application is constrained by its poor solvency, precariousness, and poisonous quality. Biocompatible, directed sterically stabilized micelles (SSM) have been utilized as nanocarriers for (CPT-SSM). SSM made out of PEGylated phospholipids are appealing nanocarriers for CPT conveyance on account of their size (14 $\mathrm{nm}$ ) and capacity to extravasate through the flawed microvasculature of tumors and aggravated tissues. This latent focusing on results in high medication fixation in tumors and decreased medication harmfulness to the ordinary tissues [114].

\section{Lower dose}

Drug dose deliveries through NPs are 1000 times less than the free drug dose demand for similar developed state of tumor [114]. The portion of aerosolized liposomal 9-nitrocamptothecin was the lower aerosolized portion required to accomplish comparative 9-nitrocamptothecin plasma levels to those found in the oral course. A few patients engaged with the preliminary reacted mostly to the treatment building up the remedial capability of aspiratory organization of 9-nitrocamptothecin detailed in a liposome [118].

\section{Secure against degradation}

NDS could shield the medications from corruption by chemicals show in the epithelial covering liquids. NDS present a few potential outcomes to improve medicines of the upper aviation routes like they could shield the medications from corruption by compounds present in the epithelial coating liquids [108].

\section{Improved drug delivery to the lungs}

Targeted conveyance framework for nanotechnology is a moderately new idea, particularly when appropriate to IPF. Nano-based frameworks are deliberately intended to upgrade the helpful record of medications utilized for IPF treatment through enhancement of its bioavailability, stability, and residency at focused lung districts. Alongside these advantages, nano-based frameworks likewise give extra indicative points of interest amid the treatment of IPF. Before long, movements of nano-based medications through the aspiratory organization to lung disease therapies are still in its earliest stages, along with various difficulties, are expected.

\section{CONCLUSION}

IPF has more awful anticipation than numerous kinds of malignancy. Medications can defer the movement of the ailment yet most likely cannot convey it to a changeless stop. We review IPF and support that NPs are significant to target alveoli epithelial cells. Contrasted with nanocarriers, the significant downside of microparticles is their more noteworthy powerlessness to phagocytosis by alveolar macrophages. Interestingly, nanocarriers escape all the greater effortlessly freedom instruments into the lungs. The inhalation of NPs targets the fibrosis based upon size and surface properties. Moreover, the surface of nanocarriers can be functionalized, keeping in mind the end goal to influence their connections with the lung condition and direct their destiny in special pathways. The scale of NPs allows them to be accumulated in the lungs at a higher efficiency than larger-sized particles, which would ultimately produce higher in smaller doses and higher bio-persistence.

Particle adhesion, lung aggregation, and retention as well as extended-release properties of NPs can contribute to enhanced and prolonged therapeutic effects, resulting in longer dose times and better patient compliance. In addition, based on their size, NPs can be quickly embedded into particles or aerosolized into droplets with 
aerodynamically compatible properties, enabling ample deposition of an active compound in the deep lung. In fact, nanosized particles bind to the lung's mucosal surface for a prolonged period of time relative to bigger particles because of the small size.

\section{ACKNOWLEDGMENTS}

The authors would like to thank Dr. Praful Bharadiya, Dr. Mihir Raval, and Dr. Dhaval Mori for their helpful comments.

\section{AUTHORS' CONTRIBUTIONS}

The authors, Ms. Kiran Dudhat and Dr. Harsha Patel, take considerably subsidized to the writing of this review article. Ms. Kiran Dudhat, who is the first author, has played a critical part in this article. She recommended the theme and helped out in procurement and understanding of the information in the article. She has done the literature review and investigated the utmost relevant articles for the review. The last author, who is Dr. Harsha Patel, is Ph.D. guide in GTU and Principal of I.I.C.P., who reviewed the article judgmentally for its knowledgeable content and assisted in the concluding endorsement of the version to be published.

\section{CONFLICTS OF INTEREST}

The authors affirm no conflicts of interest, financial, or otherwise.

\section{CONSENT FOR PUBLICATION}

Not applicable.

\section{FUNDING}

No.

\section{REFERENCES}

1. Kolb M, Bonella F, Wollin L. Therapeutic targets in idiopathic pulmonary fibrosis. Resp Med 2017;131:49-57.

2. Hutchinson J, Fogarty A, Hubbard R, McKeever T. Global incidence and mortality of idiopathic pulmonary fibrosis: A systematic review. Eur Res J 2015:46:795-806.

3. Soo E, Adamali H, Edey A. Idiopathic pulmonary fibrosis: Current and future directions. Clin Radiol 2017:72:343-55.

4. Gross TJ, Hunninghake GW. Idiopathic pulmonary fibrosis. N Eng J Med 2001;345:517-25.

5. Kamp DW. Idiopathic pulmonary fibrosis: The inflammation hypothesis revisited. Chest 2003;124:1187-90.

6. Kropski JA, Pritchett JM, Zoz DF, Crossno PF, Markin C, Garnett ET, et al. Extensive phenotyping of individuals at risk for familial interstitial pneumonia reveals clues to the pathogenesis of interstitial lung disease. Am J Res Crit Care Med 2015;191:417-26.

7. Ley B, Collard HR. Epidemiology of idiopathic pulmonary fibrosis. Clin Epidemiol 2013;5:483.

8. Taskar VS, Coultas DB. Is idiopathic pulmonary fibrosis an environmental disease? Am Thoracic Soc 2006;3:293-8.

9. Iwai K, Mori T, Yamada N, Yamaguchi M, Hosoda Y. Idiopathic pulmonary fibrosis. Epidemiologic approaches to occupational exposure. Am J Res Crit Care Med 1994;150:670-5.

10. Kaunisto J, Salomaa ER, Hodgson U, Kaarteenaho R, Kankaanranta H, Koli K, et al. Demographics and survival of patients with idiopathic pulmonary fibrosis in the FinnishIPF registry. ERJ Open Res 2019;5:00170.

11. Rudd RM, Prescott RJ, Chalmers J, Johnston ID. British thoracic society study on cryptogenic fibrosing alveolitis: Response to treatment and survival. Thorax 2007;62:62-6.

12. Panos RJ, Mortenson RL, Niccoli SA, King TE Jr. Clinical deterioration in patients with idiopathic pulmonary fibrosis: Causes and assessment. Am J Med 1990;88:396-404.

13. Gottlieb AJ, Spiera H, Teirstein AS, Siltzbach LE. Serologic factors in idiopathic diffuse interstitial pulmonary fibrosis. Am J Med 1965;39:405-10

14. Du Bois R, Wells A. Cryptogenic fibrosing alveolitis/idiopathic pulmonary fibrosis. Eur Res J 2001;18:43s-55.

15. du Bois RM. An earlier and more confident diagnosis of idiopathic pulmonary fibrosis. Eur Resp Rev 2012;21:141-6.

16. Raghu G, Collard HR, Egan JJ, Martinez FJ, Behr J, Brown KK, et al. An official ATS/ERS/JRS/ALAT statement: Idiopathic pulmonary fibrosis: Evidence-based guidelines for diagnosis and management. Am J Res Crit Care Med 2011;183:788-824.

17. Prasad R, Gupta N, Singh A, Gupta P. Diagnosis of idiopathic pulmonary fibrosis: Current issues. Intractable Rare Dis Res 2015;4:65-9.

18. Cottin V, Cadranel J, Crestani B, Dalphin JC, Delaval P, Israel-Biet $\mathrm{D}$, et al. Management of idiopathic pulmonary fibrosis in France: A survey of 1244 pulmonologists. Res Med 2014;108:195-202.

19. Valeyre D. Towards a better diagnosis of idiopathic pulmonary fibrosis. Eur Respir Rev 2011;20:108-13.

20. Richeldi L, Du Bois RM, Raghu G, Azuma A, Brown KK, Costabel $\mathrm{U}$, et al. Efficacy and safety of nintedanib in idiopathic pulmonary fibrosis. N Eng J Med 2014;370:2071-82.

21. Canestaro WJ, Forrester SH, Raghu G, Ho L, Devine BE. Drug treatment of idiopathic pulmonary fibrosis: Systematic review and network meta-analysis. Chest 2016;149:756-66.

22. King TE Jr., Bradford WZ, Castro-Bernardini S, Fagan EA, Glaspole I, Glassberg MK, et al. A Phase 3 trial of pirfenidone in patients with idiopathic pulmonary fibrosis. N Eng J Med 2014;370:2083-92.

23. Hayton C, Chaudhuri N. Current treatments in the management of idiopathic pulmonary fibrosis: Pirfenidone and nintedanib. Clin Med Insights Ther 2017;9:126.

24. Cottin V. The role of pirfenidone in the treatment of idiopathic pulmonary fibrosis. Respir Res 2013;14:S5.

25. Cottin V, Maher T. Long-term clinical and real-world experience with pirfenidone in the treatment of idiopathic pulmonary fibrosis. Eur Respir Rev 2015;24:58-64.

26. Azuma A. Pirfenidone treatment of idiopathic pulmonary fibrosis. Ther Adv Res Dis 2012;6:107-14.

27. Idiopathic Pulmonary Fibrosis Clinical Research Network. Prednisone, azathioprine, and N-acetylcysteine for pulmonary fibrosis. N Eng J Med 2012;366:1968-77.

28. Wells A, Behr J, Costabel U, Cottin V, Poletti V. Triple therapy in idiopathic pulmonary fibrosis: An alarming press release. Eur Respir Soc 2012;39:805-6

29. Douglas WW, Ryu JH, Schroeder DR. Idiopathic pulmonary fibrosis: Impact of oxygen and colchicine, prednisone, or no therapy on survival. Am J Respir Crit Care Med 2000;161:1172-8.

30. Weg JG, Haas CF. Long-term oxygen therapy for COPD: Improving longevity and quality of life in hypoxemic patients. Postgrad Med 1998;103:143-55.

31. Mejía M, Carrillo G, Rojas-Serrano J, Estrada A, Suárez T, Alonso D, et al. Idiopathic pulmonary fibrosis and emphysema: Decreased survival associated with severe pulmonary arterial hypertension. Chest 2009:136:10-5.

32. Kistler KD, Nalysnyk L, Rotella P, Esser D. Lung transplantation in idiopathic pulmonary fibrosis: A systematic review of the literature. BMC Pulm Med 2014;14:139.

33. Mason DP, Brizzio ME, Alster JM, McNeill AM, Murthy SC, Budev MM, et al. Lung transplantation for idiopathic pulmonary fibrosis. Ann Thoracic Surg 2007;84:1121-8

34. Raghu G, Richeldi L. Current approaches to the management of idiopathic pulmonary fibrosis. Respir Med 2017;129:24-30.

35. El-Nour KM, Eftaiha AA, Al-Warthan A, Ammar RA. Synthesis and applications of silver nanoparticles. Arab J Chem 2010;3:135-40.

36. Pandey N, Dhiman S, Srivastava T, Majumder S. Transition metal oxide nanoparticles are effective in inhibiting lung cancer cell survival in the hypoxic tumor microenvironment. Chem Biol Interact 2016;254:221-30.

37. Kawashima Y. Nanoparticulate systems for improved drug delivery. Adv Drug Deliv Rev 2001;47:1-136.

38. Nikalje AP. Nanotechnology and its applications in medicine. Med Chem 2015;5:81-9.

39. Meng $\mathrm{H}, \mathrm{Xu} \mathrm{Y}$. Pirfenidone-loaded liposomes for lung targeting: Preparation and in vitro/in vivo evaluation. Drug Des Dev Ther 2015;9:3369.

40. Togami K, Miyao A, Miyakoshi K, Kanehira Y, Tada H, Chono S. Efficient delivery to human lung fibroblasts (WI-38) of pirfenidone incorporated into liposomes modified with truncated basic fibroblast growth factor and its inhibitory effect on collagen synthesis in idiopathic pulmonary fibrosis. Biol Pharm Bull 2015;38:270-6.

41. Maiolino S, Russo A, Pagliara V, Conte C, Ungaro F, Russo G, et al. Biodegradable nanoparticles sequentially decorated with polyethyleneimine and hyaluronan for the targeted delivery of docetaxel to airway cancer cells. J Nanobiotechnol 2015;13:29.

42. Jone A. Liposomes: A short review. J Pharm Sci Res 2013;5:181. 
43. Pierre MB, Costa ID. Liposomal systems as drug delivery vehicles for dermal and transdermal applications. Arch Dermatol Res 2011;303:607.

44. Danhier F, Feron O, Préat V. To exploit the tumor microenvironment: Passive and active tumor targeting of nanocarriers for anti-cancer drug delivery. J Control Release 2010;148:135-46.

45. Guo L, Fan L, Ren J, Pang Z, Ren Y, Li J, et al. Combination of TRAIL and actinomycin D liposomes enhances antitumor effect in non-small cell lung cancer. Int J Nanomedicine 2012;7:1449.

46. Kellaway IW, Farr SJ. Liposomes as drug delivery systems to the lung. Adv Drug Deliv Rev 1990;5:149-61.

47. Kraft JC, Freeling JP, Wang Z, Ho RJ. Emerging research and clinical development trends of liposome and lipid nanoparticle drug delivery systems. J Pharm Sci 2014;103:29-52.

48. Chennakesavulu S, Mishra A, Sudheer A, Sowmya C, Reddy SC, Bhargav E. Pulmonary delivery of liposomal dry powder inhaler formulation for effective treatment of idiopathic pulmonary fibrosis. Asian J Pharm Sci 2018;13:91-100.

49. Wang Q, Wu P, Ren W, Xin K, Yang Y, Xie C, et al. Comparative studies of salinomycin-loaded nanoparticles prepared by nanoprecipitation and single emulsion method. Nanoscale Res Lett 2014;9:351.

50. Rudokas M, Najlah M, Alhnan MA, Elhissi A. Liposome delivery systems for inhalation: A critical review highlighting formulation issues and anticancer applications. Med Princ Pract 2016;25:60-72.

51. Zhang L, Gu F, Chan J, Wang AZ, Langer RS, Farokhzad OC. Nanoparticles in medicine: Therapeutic applications and developments. Clin Pharmacol Ther 2008:83:761-9.

52. Yhee JY, Im J, Nho RS. Advanced therapeutic strategies for chronic lung disease using nanoparticle-based drug delivery. J Clin Med 2016;5:82.

53. Schuster BS, Suk JS, Woodworth GF, Hanes J. Nanoparticle diffusion in respiratory mucus from humans without lung disease. Biomaterials 2013:34:3439-46

54. Kesharwani P, Jain K, Jain NK. Dendrimer as nanocarrier for drug delivery. Prog Polym Sci 2014;39:268-307.

55. Mendes LP, Pan J, Torchilin VP. Dendrimers as nanocarriers for nucleic acid and drug delivery in cancer therapy. Molecules 2017;22:1401.

56. Bharatwaj B, Mohammad AK, Dimovski R, Cassio FL, Bazito RC, Conti D, et al. Dendrimer nanocarriers for transport modulation across models of the pulmonary epithelium. Mol Pharm 2015;12:826-38.

57. Jeong Y, Kim ST, Jiang Y, Duncan B, Kim CS, Saha K, et al. Nanoparticle-dendrimer hybrid nanocapsules for therapeutic delivery. Nanomedicine 2016;11:1571-8.

58. Inapagolla R, Guru BR, Kurtoglu Y, Gao X, Lieh-Lai M, Bassett DJ, et al. In vivo efficacy of dendrimer-methylprednisolone conjugate formulation for the treatment of lung inflammation. Int J Pharm 2010;399:140-7

59. Loira-Pastoriza C, Todoroff J, Vanbever R, Delivery strategies for sustained drug release in the lungs. Adv Drug Deliv Rev 2014;75:81-91.

60. Haque S, McLeod VM, Jones S, Fung S, Whittaker M, McIntosh M, et al. Effect of increased surface hydrophobicity via drug conjugation on the clearance of inhaled PEGylated polylysine dendrimers. Eur J Pharm Biopharm 2017:119:408-18.

61. Faraji AH, Wipf P. Nanoparticles in cellular drug delivery. Bioorg Med Chem 2009; 17:2950-62.

62. Cho EC, Glaus C, Chen J, Welch MJ, Xia Y. Inorganic nanoparticlebased contrast agents for molecular imaging. Trends Mol Med 2010;16:561-73.

63. Swierczewska M, Lee S, Chen X. Inorganic nanoparticles for multimodal molecular imaging. Mol Imaging 2011;10:3-16.

64. Ding Y, Jiang Z, Saha K, Kim CS, Kim ST, Landis RF, et al. Gold nanoparticles for nucleic acid delivery. Mol Ther 2014;22:1075-83.

65. Capek I. DNA Engineered Noble Metal Nanoparticles: Fundamentals and State-of-the-art of Nanobiotechnology. United States: John Wiley \& Sons; 2015

66. Geiser M, Quaile O, Wenk A, Wigge C, Eigeldinger-Berthou S, Hirn S, et al. Cellular uptake and localization of inhaled gold nanoparticles in lungs of mice with chronic obstructive pulmonary disease. Part Fibre Toxicol 2013;10:19

67. Chen HW, Su SF, Chien CT, Lin WH, Yu SL, Chou CC, et al. Titanium dioxide nanoparticles induce emphysema-like lung injury in mice. FASEB J 2006;20:2393-5

68. Shi H, Magaye R, Castranova V, Zhao J. Titanium dioxide nanoparticles: A review of current toxicological data. Part Fibre Toxicol 2013;10:15.

69. Shrikhande SS, Jain DS, Athawale RB, Bajaj AN. Nanoparticulate drug delivery systems for treatment of hepatocellular carcinoma. Curr Cancer Ther Rev 2014;10:22-33.

70. Muralidharan P, Malapit M, Mallory E, Hayes D Jr., Mansour HM.
Inhalable nanoparticulate powders for respiratory delivery. Nanomedicine 2015;11:1189-99.

71. Dehghan S, Kheiri MT, Tabatabaiean M, Darzi S, Tafaghodi M. Drypowder form of chitosan nanospheres containing influenza virus and adjuvants for nasal immunization. Arch Pharm Res 2013;36:981-92.

72. Kilic A, Capan Y, Vural I, Gursoy RN, Dalkara T, Cuine A, et al. Preparation and characterization of PLGA nanospheres for the targeted delivery of NR2B-specific antisense oligonucleotides to the NMDA receptors in the brain. J Microencapsul 2005;22:633-41.

73. Stella B, Arpicco S, Rocco F, Marsaud V, Renoir JM, Cattel L, et al. Encapsulation of gemcitabine lipophilic derivatives into polycyanoacrylate nanospheres and nanocapsules. Int J Pharm 2007;344:71-7

74. Pitard B, Bello-Roufaï M, Lambert O, Richard P, Desigaux L, Fernandes S. et al. Negatively charged self-assembling DNA/ poloxamine nanospheres for in vivo gene transfer. Nucleic Acids Res 2004;32:e159

75. Richard-Fiardo P, Cambien B, Pradelli E, Beilvert F, Pitard B, SchmidAntomarchi $\mathrm{H}$, et al. Effect of fractalkine-Fc delivery in experimental lung metastasis using DNA/704 nanospheres. Cancer Gene Ther 2011;18:761-72

76. Kuzmov A, Minko T. Nanotechnology approaches for inhalation treatment of lung diseases. J Control Release 2015;219:500-18.

77. Nishimoto K, Mimura A, Aoki M, Banura N. Application of magnetic particle imaging to pulmonary imaging using nebulized magnetic nanoparticles. Open J Med Imaging 2015;5:49.

78. Graczyk H, Bryan LC, Lewinski N, Suarez G, Coullerez G, Bowen P, et al. Physicochemical characterization of nebulized superparamagnetic iron oxide nanoparticles (SPIONs). J Aerosol Med Pulm Drug Deliv 2015;28:43-51.

79. Verma NK, Crosbie-Staunton K, Satti A, Gallagher S, Ryan KB, Doody T, et al. Magnetic core-shell nanoparticles for drug delivery by nebulization. J Nanobiotechnol 2013;11:1

80. Weber S, Zimmer A, Pardeike J. Solid lipid nanoparticles (SLN) and nanostructured lipid carriers (NLC) for pulmonary application: A review of the state of the art. Eur J Pharm Biopharm 2014;86:7-22.

81. Nguyen KT, Zhao Y. Engineered hybrid nanoparticles for on-demand diagnostics and therapeutics. Acc Chem Res 2015;48:3016-25.

82. Sgorla D, Bunhak EJ, Cavalcanti OA, Fonte P, Sarmento B. Exploitation of lipid-polymeric matrices at nanoscale for drug delivery applications. Expert Opin Drug Deliv 2016;13:1301-9.

83. Hadinoto K, Sundaresan A, Cheow WS. Lipid-polymer hybrid nanoparticles as a new generation therapeutic delivery platform: A review. Eur J Pharm Biopharm 2013;85:427-43.

84. Clawson C, Ton L, Aryal S, Fu V, Esener S, Zhang L. Synthesis and characterization of lipid-polymer hybrid nanoparticles with $\mathrm{pH}$-triggered poly (ethylene glycol) shedding. Langmuir 2011;27:10556-61.

85. Zhang L, Feng Q, Wang J, Zhang S, Ding B, Wei Y, et al. Microfluidic synthesis of hybrid nanoparticles with controlled lipid layers: Understanding flexibility-regulated cell-nanoparticle interaction. ACS Nano 2015;9:9912-21

86. Zhang L, Zhang L. Lipid-polymer hybrid nanoparticles: Synthesis, characterization and applications. Nano Life 2010;1:163-73.

87. Ragelle H, Colombo S, Pourcelle V, Vanvarenberg K, Vandermeulen G, Bouzin $\mathrm{C}$, et al. Intracellular siRNA delivery dynamics of integrintargeted, PEGylated chitosan-poly (ethylene imine) hybrid nanoparticles: A mechanistic insight. J Control Release 2015;211:1-9.

88. Li R, Wu W, Liu Q, Wu P, Xie L, Zhu Z, et al. Intelligently targeted drug delivery and enhanced antitumor effect by gelatinase-responsive nanoparticles. PLoS One. 2013;8:e69643.

89. van Vlerken LE, Vyas TK, Amiji MM. Poly (ethylene glycol)-modified nanocarriers for tumor-targeted and intracellular delivery. Pharm Res 2007;24:1405-14

90. Ungaro F, d'Angelo I, Coletta C, d'Emmanuele di Villa Bianca R, Sorrentino R, Perfetto B, et al. Dry powders based on PLGA nanoparticles for pulmonary delivery of antibiotics: Modulation of encapsulation efficiency, release rate and lung deposition pattern by hydrophilic polymers. J Control Release 2012;157:149-59.

91. Fahmi A, Appelhans D, Cheval N, Pietsch T, Bellmann C, Gindy N, et al. Hybrid nanoalloy: Nanofibers fabricated by self-assembling dendrimers mediate in situ CdSe quantum dots and their metallization with discrete gold nanoparticles. J Adv Mater 2011;23:3289-93.

92. Kaminskas LM, McLeod VM, Ryan GM, Kelly BD, Haynes JM, Williamson $\mathrm{M}$, et al. Pulmonary administration of a doxorubicinconjugated dendrimer enhances drug exposure to lung metastases and improves cancer therapy. J Control Release 2014;183:18-26.

93. Dames P, Gleich B, Flemmer A, Hajek K, Seidl N, Wiekhorst F, 
et al. Targeted delivery of magnetic aerosol droplets to the lung. Nat Nanotechnol 2007;2:495.

94. Ali J, Ali M, Baboota S. Patents on nanoparticulate drug delivery systems-a review. Recent Pat Drug Deliv Formul 2008;2:83-9.

95. Paranjpe M, Müller-Goymann CC. Nanoparticle-mediated pulmonary drug delivery: A review. Int J Mol Sci 2014;15:5852-73.

96. Garbuzenko OB, Ivanova V, Kholodovych V, Reimer DC, Reuhl KR, Yurkow E, et al. Combinatorial treatment of idiopathic pulmonary fibrosis using nanoparticles with prostaglandin $\mathrm{E}$ and siRNA(s). Nanomedicine 2017;13:1983-92.

97. Azarmi S, Roa WH, Löbenberg R. Targeted delivery of nanoparticles for the treatment of lung diseases. Adv Drug Deliv Rev 2008;60:863-75.

98. Savla R, Minko T. Nanotechnology approaches for inhalation treatment of fibrosis. J Drug Target 2013;21:914-25.

99. Jiang HL, Hong SH, Kim YK, Islam MA, Kim HJ, Choi YJ, et al. Aerosol delivery of spermine-based poly (amino ester)/Akt1 shRNA complexes for lung cancer gene therapy. Int J Pharm 2011;420:256-65.

100. Pilcer G, Amighi K. Formulation strategy and use of excipients in pulmonary drug delivery. Int J Pharm 2010;392:1-19.

101. Al-Qadi S, Grenha A, Carrión-Recio D, Seijo B, Remuñán-López C. Microencapsulated chitosan nanoparticles for pulmonary protein delivery: In vivo evaluation of insulin-loaded formulations. J Control Release 2012;157:383-90.

102. Grenha A, Remuñán-López C, Carvalho EL, Seijo B. Microspheres containing lipid/chitosan nanoparticles complexes for pulmonary delivery of therapeutic proteins. Eur J Pharm Biopharm 2008;69:83-93.

103. Li YZ, Sun X, Gong T, Liu J, Zuo J, Zhang ZR. Inhalable microparticles as carriers for pulmonary delivery of thymopentin-loaded solid lipid nanoparticles. Pharm Res 2010;27:1977-86.

104. McDonald G. Topically Active Steroids for Use in Interstitial Pulmonary Fibrosis. United States: Google Patents; 2017.

105. Pople PV, Singh KK. Development and evaluation of topical formulation containing solid lipid nanoparticles of Vitamin A. AAPS PharmSciTech 2006;7:E63-9.

106. Silva AL, Santos RS, Xisto DG, Alonso SD, Morales MM, Rocco PR, et al. Nanoparticle-based therapy for respiratory diseases. An Acad Bras Cienc 2013;85:137-46.

107. Stern ST, McNeil SE. Nanotechnology safety concerns revisited. Toxicol Sci 2008;101:4-21.

108. Boland S, Guadagnini R, Baeza-Squiban A, Hussain S, Marano F. Nanoparticles used in medical applications for the lung: Hopes for nanomedicine and fears for nanotoxicity. J Phys Conf Ser 2011;304:16-8.

109. Iyer R, Hsia CC, Nguyen KT. Nano-therapeutics for the lung: State-ofthe-art and future perspectives. Curr Pharm Des 2015;21:5233-44.

110. Pandey R, Sharma A, Zahoor A, Sharma S, Khuller GK, Prasad B. Poly (DL-lactide-co-glycolide) nanoparticle-based inhalable sustained drug delivery system for experimental tuberculosis. J Antimicrob Chemoth 2003;52:981-6.

111. Banerjee ER. Idiopathic lung fibrosis model for drug discovery. In: Perspectives in Translational Research in Life Sciences and Biomedicine. Berlin, Germany: Springer; 2016. p. 13-31.

112. Zahoor A, Sharma S, Khuller G. Inhalable alginate nanoparticles as antitubercular drug carriers against experimental tuberculosis. Int J Antimicrob Agents 2005;26:298-303.

113. Ramos-Cabrer P, Campos F. Liposomes and nanotechnology in drug development: Focus on neurological targets. Int J Nanomed 2013;8:951.

114. Singh R, Lillard JW Jr. Nanoparticle-based targeted drug delivery. Exp Mol Pathol 2009;86:215-23.

115. Byrne JD, Baugh JA. The significance of nanoparticles in particleinduced pulmonary fibrosis. McGill J Med 2008;11:43.

116. Gradauer K, Barthelmes J, Vonach C, Almer G, Mangge H, Teubl B, et al. Liposomes coated with thiolated chitosan enhance oral peptide delivery to rats. J Control Release 2013;172:872-8

117. Longmire M, Choyke PL, Kobayashi H. Clearance properties of nanosized particles and molecules as imaging agents: Considerations and caveats. Nanomedicine (Lond) 2008;3:703-17.

118. Lee WH, Loo CY, Traini D, Young PM. Inhalation of nanoparticlebased drug for lung cancer treatment: Advantages and challenges. Asian J Pharm Sci 2015;10:481-9. 